\title{
AS RELAÇÕES INTERPESSOAIS E A JUSTIÇA RESTAURATIVA NA ESCOLA
}

\author{
Lara Cucolicchio Lucatto, Raul Aragão Martins \\ Universidade Estadual Paulista Júlio de Mesquita Filho - UNESP, Programa de Pós Graduação em Educação. \\ Marília/SP.E-mail:Ialucatto@gmail.com \\ Agência de fomento: Capes
}

\section{RESUMO}

A presente pesquisa teve como objetivo investigar as relações interpessoais na escola que adotou o Projeto de Justiça Restaurativa. Caracterizou-se como um estudo qualitativo, fundamentado na teoria construtivista piagetiana. Os dados foram coletados por meio de observação do ambiente escolar, entrevista semiestruturada e analisados pela triangulação das informações. Os resultados evidenciaram que a implantação dos Círculos Restaurativos, um dos procedimentos da Justiça Restaurativa, não influenciou a qualidade das relações interpessoais dessa amostra. Apesar do resultado, o Projeto da Justiça Restaurativa, se configura, como mais um fator de proteção de que podemos lançar mão num contexto socioeducacional na formação integral do indivíduo.

Palavras-chave: desenvolvimento-moral, justiça restaurativa, relações interpessoais, conflitos interpessoais, construtivismo

\section{INTERPERSONAL RELATIONSHIPS AND RESTORATIVE SCHOOL}

\section{ABSTRACT}

This research aimed to investigate the interpersonal relationships in the school that adopted the Restorative Justice Project. It was characterized as a qualitative study, based on Piaget's constructivist theory. Data were collected through observation of the school environment, semistructured interviews and analyzed by triangulation of information. The results showed that the implementation of Restorative Circles, one of the procedures of the Restorative Justice, did not influence the quality of interpersonal relationships in this sample. Despite the result, the Restorative Justice Project is one more protection factor that we can use in social and educational context to promote the individual's integral formation.

Keywords: moral developmente, restorative justice, interpesonal relationships, interpersonal conflicts, constructivism 


\section{INTRODUÇÃO}

A instituição educativa tem como objetivo, formar integralmente seus alunos, e isso inclui a formação moral, no entanto, tem encontrado dificuldades para essa missão. O que pode ser constatado, entre outros fatores, pela não interação ou pelas formas submissas ou agressivas pelos quais os conflitos interpessoais são resolvidos. Os profissionais da educação têm procurado intervir nessas situações, mas sem grande êxito.

Com uma visão tradicional acredita que os conflitos sejam ocorrências atípicas e que não fazem parte do currículo, são compreendidos como prejudiciais ao bom andamento das relações entre os alunos (VINHA ,2003). Partindo dessa premissa, tenta evitá-los, resolvê-los rapidamente ou os ignorá-los (principalmente quando ocorrem entre os pares). Por serem vistos como negativos, apresentam soluções prontas, unilaterais, punem, ameaçam.

Apesar desses mecanismos de controle muitas vezes "funcionarem" no presente, não contribuem para o desenvolvimento moral dos alunos, que em longo prazo podem apresentar dificuldades para: emitir opiniões, argumentar e ouvir perspectivas diferentes sem sentir-se ameaçado, tomar decisões, expor e discutir seus sentimentos, resolver seus conflitos de forma justa, respeitosa e satisfatória para todos, além disso, pode ainda sentir revolta, aprender a mentir, fazer "cálculo de risco" diante de uma situação (VINHA, 2003).

Os conflitos na perspectiva construtivista são oportunidades de desenvolvimento e aprendizagem, fornecendo indícios sobre o que as crianças precisam aprender. Lidar com o conflito compreendendo que eles pertencem aos envolvidos, mas isso não significa largá-los a própria sorte, o professor deverá fazer o papel de mediador no processo, auxiliando um a ouvir o outro, a exporem seus sentimentos sem causar dano, a pensar em soluções boas e satisfatórias para os dois lados.

Diante das dificuldades no âmbito escolar, pesquisadores de diversos países propõem procedimentos e Projetos que têm como objetivo favorecer a construção da autonomia, a apropriação racional das normas e valores, assim como o desenvolvimento de formas mais dialógicas, justas e respeitosas para lidar com os conflitos (ARAÚJO, 2004; LEME, 2004; SASTRE, MORENO, 2002; PUIG , 2000; VINHA, 2003). Oriundo do âmbito jurídico, o Projeto de Justiça Restaurativa na escola propõe uma mudança de uma lógica punitiva para uma restaurativa. De acordo com esse novo paradigma, são utilizados alguns procedimentos que visam mediar os conflitos, melhorar o convívio escolar e prevenir a violência. Dentre tais procedimentos, há o Círculo Restaurativo, que se caracteriza por ser um procedimento de resolução de conflitos no âmbito privado.

De acordo com Melo (2005), no modelo vigente de justiça, mesmo que esteja presente a ideia de aplicar a pena tanto para punir como para reeducar o infrator, não tem havido contribuição efetiva para a reeducação ou para uma melhora social. Da mesma forma que a concepção de Justiça Restaurativa influenciou o sistema judiciário de várias nações, tal influência também se estendeu a outra instituição em que os conflitos estão sempre presentes: a escola. Além de propor procedimentos mais cooperativos para resolver os conflitos e, simultaneamente, promover a autorresponsabilização e a reparação dos danos, o trabalho com a Justiça Restaurativa pretende, ainda, que haja a vivência cotidiana desta prática restaurativa nas diversas dimensões da escola, de maneira que se promova continuamente a constituição de relações interpessoais mais harmoniosas e recíprocas, bem como o diálogo, o sentimento de pertencimento à comunidade escolar e o incentivo à realização de escolhas e à assunção de responsabilidades pelos alunos.

Vários trabalhos já evidenciaram a importância que essas relações interpessoais possuem e a influência que desempenham para a aprendizagem e para o desenvolvimento de valores, como a moral. Dentre eles, podemos citar o estudo realizado por Perkins (2011), no qual o clima escolar é mencionado como fator de forte influência sobre a aprendizagem dos alunos. Ele afirma que 
características como estrutura física, relações entre pessoas e contexto psicológico podem alterar negativa ou positivamente o clima na escola e terem como resultado maior ou menor desenvolvimento dos alunos. Sendo assim, itens como respeito, confiança e a sensação de segurança foram considerados, de acordo com esse estudo, como fundamentais para a constituição da atmosfera psicológica e, consequentemente, para o bom relacionamento interpessoal dos envolvidos. Diante dessa perspectiva que enfoca o clima escolar e as relações interpessoais como fatores de suma importância para a aprendizagem e desenvolvimento moral, o objetivo da pesquisa que está sendo relatada foi investigar a influência da implantação dos Círculos Restaurativos nas relações entre os alunos e entre os professores e os alunos.

\section{MÉTODO}

Para alcançarem-se os objetivos propostos, foi selecionada uma instituição escolar cujos profissionais participaram da formação e implantação do Projeto da Justiça Restaurativa na escola desde 2005, intitulada de A em nossa análise. Foi escolhida também uma segunda escola (intitulada de B), que possuía características similares à primeira, mas nunca realizou os Círculos, servindo como parâmetro de referência. Os participantes da pesquisa foram estudantes do 6ㅇ e do 70 anos do Ensino Fundamental, professores e a equipe de especialistas de ambas as escolas, além dos alunos que vivenciaram os Círculos Restaurativos da primeira instituição. Os dados foram coletados por meio de sessões de observação, pelo recolhimento de documentos e por entrevistas clínicas. Procuramos realizar uma análise qualitativa a partir da triangulação dos dados. A pesquisa foi enviada ao Comitê de Ética da faculdade e aprovada, atendendo todos os critérios de execução, tendo como número de parecer no CEP: 832/2010. CAAE:4446.0.000.146-10.

\section{RESULTADOS}

A partir da análise qualitativa, foi possível constatar, que tanto na escola $A$, quanto na $B$, observou-se o mesmo tipo de ambiente e de conflitos entre os alunos, como xingamentos e usos de palavras ofensivas, a partir das provocações. Entre as agressões verbais, encontramos apelidos pejorativos e expressões de baixo calão, insultando, como exemplo, as mães uns dos outros com o intuito de atingir e irritar o colega. Tal fato era particularmente ofensivo para os jovens. "No geral, os motivos indicados pelos alunos para a ocorrência de tais brigas (agressões físicas ou verbais), na sua maior parte, eram: fofocas, gozações, xingamentos ou provocações" (RUOTTI et al., 2006, p. 96).

Nos contextos observados, as provocações geralmente aconteciam a partir das "brincadeiras de papel" e das "brincadeiras de mão", como por exemplo, a ação de alguns alunos passarem entre as carteiras e desferirem tapas na cabeça dos colegas. A reação dos agredidos era diversa: muitos não faziam nada, apenas resmungavam um pouco; outros revidavam o tapa e alguns xingavam o agressor.

\section{DISCUSSÃO DOS RESULTADOS}

A provocação, segundo Licciardi (2010), reflete a satisfação do sujeito ao perceber que incomodou o outro, sentindo-se superior, com poder, por ter a capacidade de atingi-lo com suas ações, essas ações se enquadram no tipo de conflito categorizado como "ação provocativa", no qual o sujeito tem o intuito de irritar o outro, seja com manifestações verbais, seja com cutucões, ou estragando algo, ou impedindo-o de realizar algo, entre outras formas de provocação. Outra forma recorrente de provocação acontecia quando alguns alunos, ao passarem próximos de um colega, esbarravam nele intencionalmente a fim de deixá-lo irritado ou colocavam o pé na frente para o colega tropeçar.

Os indivíduos em situação conflituosa têm maneiras distintas de resolvê-las. Os estilos de resolução foram categorizados em três grupos, segundo Deluty (1985) agressivo, o submisso e o 
assertivo. O indivíduo com estilo agressivo utiliza a coerção em situações conflitantes, expressando seus sentimentos de forma impositiva e unilateral; os submissos não enfrentam a situação, se submetem e acatam a perspectiva do outro, mudam de espaço físico, ficam calados tentando se esquivar das desavenças, levam mais em conta os sentimentos dos outros em detrimento dos seus; e os assertivos são aqueles que enfrentam a situação sem utilizar coação, força física ou agressão verbal, expressando seu desejo e ponto de vista, e valorizando o do próximo.

Mesmo havendo diferentes formas de resolução, as agressivas e submissas foram as predominantes no espaço escolar. Acredita-se que os Círculos Restaurativos sejam uma forma muito adequada de se resolver conflitos, pois se pautam na reflexão, na empatia, no empoderamento, no senso de justiça e na definição de ações positivas, que são os princípios de resolução assertiva de conflitos. As aprendizagens referentes a essa experiência e os resultados decorrentes, se constantemente utilizados, deveriam promover relações mais cooperativas, devido a mudanças das noções de justiça e de conflito. Contudo, isso não ocorreu com os indivíduos de nossa pesquisa, até porque não houve respeito a esse processo.

Os discentes se incomodavam com as ações dos colegas, mas não entendiam essas ações como desrespeito ou injustiça, e sim como brincadeiras. Pelos relatos, muitos alunos demonstraram se sentirem impotentes com relação aos maus tratos vivenciados. Tais dados encontram certa similaridade com os identificados por Menin (2005). Esta autora realizou uma ampla pesquisa com 480 adolescentes de ambos os sexos, de escolas públicas e particulares, que investigou as concepções de adolescentes sobre a lei, o crime, de injustiça e de imputabilidade penal. O objetivo foi verificar as diferenças dessas concepções a partir das seguintes variáveis: gênero e status econômico. Em relação à concepção de injustiça, pôde concluir que não há uma concepção bem definida, sendo maior esta dificuldade na escola pública.

Por conseguinte, quanto mais baixo o status econômico, maior foi a dificuldade para representar, conceituar e exemplificar injustiça. Ao investigar se os entrevistados já tinham presenciado situações de injustiça, os resultados mostraram que, em ambas as classes, a porcentagem dos que presenciaram foi maior do que a dos que não presenciaram. No entanto, na escola pública, a porcentagem de adolescentes que presenciaram situações de injustiça foi menor, em comparação com a particular. Esse dado, para a autora, demonstra um contrassenso, visto que o esperado era uma porcentagem maior para a escola pública, principalmente por se tratar de adolescentes que habitam locais de exclusão social. "É como se esses alunos não percebessem injustiças que podem estar ao seu lado" (MENIN, 2005, p. 144). Por fim, quanto às ideias relacionadas à injustiça, a maioria dos alunos associou injustiça com a questão da justiça legal, como uma infração da lei, e com a justiça retributiva. Isso demonstra, para a autora, que esses jovens apresentam uma ideia menos desenvolvida de justiça.

Foi possível constatar, portanto, em nossa pesquisa, que não havia um clima de justiça, muito menos um espírito restaurativo impregnando as ações dos educadores. Várias situações de conflitos poderiam ter sido trabalhadas pelo Círculo Restaurativo ou por uma postura de mediação, mas, ao invés disso, os professores ora ignoravam, ora mandavam os alunos para fora da sala de aula, ora preenchiam termos de notificação das agressões ocorridas, sem realizar maiores intervenções. Quando os alunos eram encaminhados à direção, na maioria das vezes, eram suspensos, notificados e até transferidos de classe.

Fica evidente uma visão ainda tradicionalista, na qual os conflitos são negativos e, portanto, devem ser contidos: os professores e diretores, em situações de desavenças e indisciplina, agem para evitá-las ou contê-las. Assim, punem os estudantes com advertências e suspensões ou tentam evitar novos conflitos, transferindo o aluno de ambiente. A atitude diante do conflito, acima relatada, não demonstra uma visão restaurativa do conflito. Não houve a escuta 
das partes envolvidas, nem a valorização do diálogo, muito menos a busca de acordos que possibilitassem a reparação dos danos causados (emocionais, materiais ou físicos).

\section{CONCLUSÕES}

A partir dos dados levantados e discutidos consideramos que existiram alguns fatores que dificultaram a prática restaurativa nessa amostra. Um dos aspectos que interferem no desenvolvimento de um novo projeto na instituição educativa, como o da presente pesquisa é a adesão de todos integrantes da escola, o que não ocorreu, pois poucos integrantes fizeram o curso de formação. Ao nosso ver, uma lacuna estrutural. A estrutura do curso de formação inclui as diversas dimensões dos integrantes da escola, tais como, a equipe gestora, os funcionários, os docentes, os alunos e a comunidade. Não basta, no plano formal, prever a participação de diversos agentes, se, na prática, nenhuma medida concreta é tomada.

Ainda nesse sentido, a inclusão ou não de um novo projeto no Projeto Político Pedagógico (PPP) diz muito sobre as futuras ações da equipe, se uma escola acredita que a forma de lidar com a violência e comportamentos inadequados são as sanções expiatórias, a retribuição, ela retratará tal posição no seu PPP. Não obstante, se se compreende que há necessidade de tratar esses problemas de outra forma, modificando o paradigma punitivo pelo restaurativo, o PPP deverá incorporar essa abordagem restaurativa. $O$ que não foi constatado pelos documentos. $O$ perfil do educador para ser facilitador é outro aspecto que pode contribuir ou dificultar. Na proposta restaurativa, o facilitador é uma pessoa que mediará os conflitos e se mostrará imparcial diante dos relatos dos envolvidos e deve mostrar-se receptivo, empático. Não obstante, um dos facilitadores era o coordenador, que demonstrava muita rigidez, apresentava atitudes coercitivas e não era bem aceito pelos alunos.

Finalmente, cumpre-nos relatar que, como toda ação nova que chega, é natural a existência de dificuldades em sua compreensão e desestruturação dos antigos paradigmas num processo a caminho de um novo equilíbrio. Isto posto, concluímos que apesar das dificuldades já elencadas na viabilização do projeto, ele se configura, ao nosso ver, como um procedimento de otimização nas resoluções dos conflitos e na mudança de uma cultura punitiva por uma cultura restaurativa, cujas metas são a valorização do indivíduo, o respeito, a construção de sua autonomia moral e intelectual.

\section{REFERÊNCIAS}

ARAÚJO, U. Assembleia escolar: um caminho para a resolução de conflitos. São Paulo: Moderna, 2004.

DELUTY, R. H. Consistency of assertive, aggressive, and submissive behavior for children. Journal of Personality and Social Psychology, v. 49, n. 4, p. 1054-1065, 1985. https://doi.org/10.1037/0022$\underline{3514.49 .4 .1054}$

LEME, M. I. S. Educação: o rompimento do círculo vicioso da violência. In: MALUF, M. R. (Org.). Psicologia Educacional: questões contemporâneas. São Paulo: Casa do Psicólogo, 2004, p. 163-185.

LICCIARDI, L. M. Investigando os conflitos entre as crianças na escola. Campinas, Unicamp, 2010.221p. Dissertação de Mestrado- Faculdade de Educação, Universidade Estadual de Campinas, Campinas, 2010.

MELO, E. R. Justiça Restaurativa e seus desafios histórico-culturais. Um ensaio crítico sobre os fundamentos ético-filosóficos da justiça restaurativa em contraposição à justiça retributiva. In: 
SLAKMON, C. R. et al. (Orgs.). Justiça Restaurativa. Brasília: Ministério da Justiça e Programa das Nações Unidas para o Desenvolvimento, 2005. p. 53-78.

MENIN, M. S. S. Representações de lei, crime e injustiça em adolescentes. Campinas: Mercado de Letras, 2005.

PERKINS, B. K. Where we learn: The CUBE Survey of Urban School Climate. Alexandria, VA: National School Boards Association, 20011. Disponível em < http://schoolclimatesurvey.com/publications.html. Acesso em: 01 fev. 2011.

PUIG, J. M. Democracia e participação escolar. São Paulo: Moderna, 2000.

RUOTTI, C.; ALVES, R.; CUBAS, V. Violência na escola: um guia para pais e professores. São Paulo: Andhep/Imprensa Oficial, 2006.

SASTRE, G; MORENO, M. Resolución de conflictos y aprendizaje emocional: una perspectiva de género. Barcelona: Gedise Editorial, 2002.

VINHA, T.P. Os conflitos interpessoais na relação educativa. Campinas: Unicamp, 2003.426p.Tese de doutorado. Faculdade de Educação da Universidade Estadual de Campinas, Unicamp, Campinas, 2003. 